\title{
Mucosal Type of Chronic Suppurative Otitis Media and the Long-Term Impact on Hearing Loss
}

Muhammad Salar-e-Azam Rajput ${ }^{1}$, Muhammad Shaheryar Ahmed Rajput ${ }^{2,3,4}$, Asif Ali Arain ${ }^{5}$, Syed S. Zaidi $^{3}$, Ahmad Hatem ${ }^{3}$, Saeed Akram ${ }^{6}$

1. Otolaryngology and Head \& Neck Surgery, Liaquat University Hospital, Hyderabad, PAK 2. Otolaryngology and Head \& Neck Surgery, Liaquat University of Medical and Health Sciences, Jamshoro, PAK 3. Otolaryngology and Head \& Neck Surgery, King Faisal Specialist Hospital and Research Centre, Riyadh, SAU 4. Otolaryngology and Head \& Neck Surgery, Aga Khan University Hospital, Karachi, PAK 5. Otolaryngology and Head \& Neck Surgery, The Indus Hospital, Karachi, PAK 6. Internal Medicine, King Faisal Specialist Hospital and Research Centre, Riyadh, SAU

Corresponding author: Muhammad Shaheryar Ahmed Rajput, drshaheryar@hotmail.com

\section{Abstract \\ Introduction}

Worldwide the chronic suppurative otitis media (CSOM) is one of the most common infectious diseases in childhood and is a common cause of impaired hearing. The disease remains a challenging entity for the healthcare system of resource-limited nations despite the advances in modern medicine. The nature of hearing loss in CSOM is mainly conductive, the sensorineural hearing loss (SNHL) is also reported in such patients. The purpose of the study was to identify SNHL in patients with the mucosal type of CSOM and to find the impact of long-term discharging ears on bone conduction (BC) thresholds.

\section{Methods}

Patients with a diagnosis of the mucosal type of CSOM were identified from the record of ENT, Head and Neck Surgery clinic between January 2019 and January 2020. The patients were divided into three groups based on the duration of the disease: groups I, II, and III for 1-5 years, 5-10 years, and 10-15 years, respectively. Pure tone audiogram was reviewed, and data of $\mathrm{BC}$ was recorded for 500, 1000, and 2000 $\mathrm{Hz}$. The descriptive frequency was calculated for SNHL in each group and group I was compared with other groups using a chi-square test. The mean BC threshold of group I was compared with other groups using a ttest. SPSS version 26 (IBM Corp., Armonk, New York) was used for statistical analysis.

\section{Results}

A total of 154 patients were included in the study. There were 73 males and 81 females. The mean age was 26 years. The minimum age was 12 years and the maximum age was 58 years. Active ear discharge was the presenting complaint in 84 patients. The right ear was involved in 88 patients, and the left ear was involved in 66 patients. SNHL was present in 30 out of 154 patients, i.e., 19.5\%. The number of patients in each of the groups I, II, and III was 95, 28, and 31, respectively. The group I was compared with group II using the chisquare test, the p-value was found not significant, i.e., $>0.05$. The group I was then compared with group III using the same statistical test, and the p-value was found significant, i.e., $<0.05$.

The mean BC threshold for an average of three speech frequencies for each of the three groups was 16.9, 18.7, and 22.9, respectively. The mean BC threshold of group I was compared with that of group II using a ttest, and the $\mathrm{p}$-value was found not significant, i.e., $>0.05$. The mean BC threshold of group I was then compared with that of group III using a t-test, and the p-value was found significant, i.e., $<0.05$.

\section{Conclusions}

The findings of our study reproduce the presence of SNHL in a sizable proportion of the patients with a mucosal type of CSOM. Furthermore, the elevation of the BC threshold also appears statistically significant on analysis in association with the protracted duration of CSOM, highlighting the adverse impact of delaying the surgical repair. However, the clinical importance remains unclear because the maximum losses in the BC threshold seen in the patients are not severe enough to necessarily make them hard of hearing. Nevertheless, these statistically significant results influence clinical thought process and measures for an early remedy, including surgery, and need to be considered in time to prevent progressively worsening hearing loss in such cases.

Categories: Family/General Practice, Otolaryngology, Infectious Disease

Keywords: hearing loss, chronic otitis media, mucosal disease, csom, snhl, mixed hearing loss 


\section{Cureus}

\section{Introduction}

Chronic suppurative otitis media (CSOM) is an inflammation of the middle ear associated with infection and characterized by a persistent otorrhoea from a perforated tympanic membrane over a month [1-3]. Two types of CSOM are recognized, a mucosal disease (safe type) and an epithelial disease (unsafe type) [3]. Worldwide the CSOM is one of the most common infectious diseases in childhood and is a common cause of impaired hearing, in particular, in resource-limited parts of the world [4,5].

Multiple episodes of acute otitis media often precede CSOM, which develops as a consequence when the natural repair mechanism of the tympanic membrane fails to completely heal the perforation. Once the CSOM is developed in early childhood it has the potential to spill over into adulthood and becomes the cause of recurring episodes of discharging ears unless the drum is repaired surgically. Therefore in adult patients, the disease usually has a long history spanning over years or even multiple decades [6,7].

The disease remains a challenging entity for the healthcare system of developing nations due to the enormous economic burden with a prevalence of 72 per thousand population [8]. Despite the many advances in health care and surgical practices globally, the impact of CSOM is overwhelming and often more noticeable in the developing countries [9].

The contributing factors to the high proportions of CSOM in these regions are over-crowding, malnutrition, poor hygiene, colonization with potentially pathogenic microorganisms in the nose and nasopharynx, and lack of easy access to standard healthcare facilities that are already very limited [10]. Pseudomonas aeruginosa, Staphylococcus aureus, Klebsiella pneumonia, Escherichia coli, and anaerobes are common causative bacteria reported in most cases of chronic otitis media [11].

However the nature of hearing loss in CSOM is often conductive due to damage to tympanic membrane or ossicles, the sensorineural hearing loss (SNHL) is also reported in such patients [12,13]. The purpose of this study was to identify SNHL in patients with the mucosal type of CSOM and to find the impact of duration of the discharging ears on bone conduction (BC) thresholds.

\section{Materials And Methods}

Patients with a diagnosis of the mucosal type of CSOM were identified from the record of ENT, Head and Neck Surgery clinic from January 2019 to January 2020. The criteria for inclusion and exclusion are shown in Table 1 .

\section{Inclusion Criteria}

Unilateral disease

\section{Exclusion Criteria}

History of head injury

History of meningitis

No previous otological or brain surgery

Incomplete record or missing PTA

\section{TABLE 1: Inclusion and exclusion criteria}

PTA: pure tone audiogram

A total of 154 patients were included in the study. Based on the duration of the disease, patients were divided into three groups: groups I, II, and III for 1-5 years, 5-10 years, and 10-15 years, respectively. Pure tone audiogram (PTA), a routine investigation for hearing assessment, was reviewed, and data of BC for three speech frequencies 500, 1000, and $2000 \mathrm{~Hz}$ were recorded for statistical analysis in SPSS version 26 (IBM Corp., Armonk, New York). Average was calculated for three speech frequencies, and threshold $>25$ decibels $(\mathrm{dB})$ was taken as a cutoff for the presence of SNHL. The descriptive frequency was calculated to identify the number of patients with SNHL in each group, and group I was compared with other groups using a chi-square test. The mean was computed for BC thresholds in each group, and group I was compared with other groups using a t-test to find the long-term impact of CSOM (mucosal type) on BC.

\section{Results}

Out of 154 patients, there were 73 males and 81 females. The mean age was 26 years. The minimum age was 12 years, and the maximum age was 58 years. Active ear discharge was the presenting complaint in 84 patients. The right ear was involved in 88 patients, and the left ear was involved in 66 patients. SNHL was present in 30 out of 154 patients, i.e., 19.5\%. These variables are shown in Table 2. 


\section{Cureus}

\begin{tabular}{|lll|}
\hline Variables & & Results \\
\hline Gender & Male & 73 \\
& Female & 81 \\
\hline Age & Mean & 26 years \\
& Range & $12-58$ years \\
\hline Ear discharge & Yes & 84 \\
& No & 70 \\
\hline Laterality & Right ear & 88 \\
& Left ear & 66 \\
\hline SNHL & Yes & 30 \\
\hline & No & 124 \\
\hline
\end{tabular}

TABLE 2: Age, gender, and clinical variables of the patients

SNHL: sensorineural hearing loss

The number of patients in each of the groups I, II, and III was 95, 28, and 31, respectively. The group I was compared with group II using the chi-square test; the p-value was found not significant, i.e., $>0.05$, as shown in Table 3.

\begin{tabular}{|c|c|c|c|c|}
\hline & & \multicolumn{2}{|l|}{ Disease Duration } & \multirow{2}{*}{$\begin{array}{l}\text { Chi-Square Test } \\
\text { p-value }\end{array}$} \\
\hline & & Group I (1-5 years) & Group II (5-10 years) & \\
\hline \multirow{2}{*}{ SNHL } & Yes & 14 & 06 & 0.399 \\
\hline & No & 81 & 22 & \\
\hline Total & & 95 & 28 & \\
\hline
\end{tabular}

\section{TABLE 3: SNHL and comparison between groups I and II}

SNHL: sensorineural hearing loss

The group I was then compared with group III using the same statistical test, and the p-value was found significant, i.e., $<0.05$ as shown in Table 4 .

\begin{tabular}{|c|c|c|c|c|}
\hline & & \multicolumn{2}{|l|}{ Disease Duration } & \multirow{2}{*}{$\begin{array}{l}\text { Chi-Square Test } \\
\text { p-value }\end{array}$} \\
\hline & & Group I (1-5 years) & Group III (10-15 years) & \\
\hline \multirow{2}{*}{ SNHL } & Yes & 14 & 10 & 0.031 \\
\hline & No & 81 & 21 & \\
\hline Total & & 95 & 31 & \\
\hline
\end{tabular}

TABLE 4: SNHL and comparison between groups I and III

SNHL: sensorineural hearing loss 
The mean BC threshold for an average of three speech frequencies for each of the three groups was 16.9, 18.7, and 22.9, respectively. The mean BC threshold of group I was compared with that of group II using a ttest, and the p-value was found not significant, i.e., >0.05 as shown in Table 5 .

\begin{tabular}{|c|c|c|c|c|}
\hline Disease Duration & $\mathbf{N}$ & Mean & Standard Deviation & t-test \\
\hline Group I (1-5 years) & 95 & 16.9 & 7.13 & \multirow{2}{*}{ p-value 0.23} \\
\hline Group II (5-10 years) & 28 & 18.7 & 6.02 & \\
\hline
\end{tabular}

\section{TABLE 5: Mean bone conduction threshold and comparison between groups I and II}

$\mathrm{N}$ : number of patients in each group

The mean BC threshold of group I was then compared with that of group III using a t-test, and the p-value was found significant, i.e., $<0.05$ as shown in Table 6.

\begin{tabular}{|c|c|c|c|c|}
\hline Disease Duration & $\mathbf{N}$ & Mean & Standard Deviation & t-test \\
\hline Group I (1-5 years) & 95 & 16.9 & 7.13 & \multirow{2}{*}{$\mathrm{p}$-value $<0.001$} \\
\hline Group III (10-15 years) & 31 & 22.9 & 8.12 & \\
\hline
\end{tabular}

\section{TABLE 6: Mean bone conduction threshold and comparison between groups I and III}

$\mathrm{N}$ : number of patients in each group

\section{Discussion}

Despite the several reports of an association between CSOM and SNHL, the consensus is still lacking about its importance. The study published in 1984 reported SNHL in the study subjects with chronic otitis media and suggested passage of inflammatory agents through the round window as a possible mechanism of cochlear damage resulting in SNHL. Additionally, it was considered the anatomical position and characteristic of the round window encourage this passage. There were two groups of patients based on the severity of hearing loss. The authors found $43 \%$ of ears with unilateral disease and $42 \%$ of ears with bilateral disease showed losses $15 \mathrm{~dB}$ or greater; group 1 . In group 2, $16 \%$ of ears with unilateral disease and $17 \%$ of ears with bilateral disease revealed losses $30 \mathrm{~dB}$ or greater. The study did not consider the effect of the duration of the disease and the use of ototoxic ear drops [14].

In 1998, El-Sayed reported the higher BC thresholds over a number of frequencies by 9 to $14 \mathrm{~dB}$. Twelve percent of the patients had a difference of $20 \mathrm{~dB}$ or more when compared to the opposite normal ears, and $39 \%$ of the patient had a difference of $10 \mathrm{~dB}$ or more [15]. Yoshida et al. in 2009 reported the percentage of patients with SNHL was likely to increase with age [16].

The conductive hearing loss which is constantly associated with CSOM is responsive to surgical treatment. On the other hand, the SNHL that follows a few years later is the result of permanent damage to the cochlea. If the treatment is delayed for years or decades the possibility of the need for a hearing aid, even after the surgical correction of the conductive defect, increases with protracting duration of the disease and recurrent infections [17].

Furthermore, a majority of adults do not want to use hearing aids (HA). A number of explanations were given, including the hearing aid value, fitting and maintenance issues, patient's attitude, economical factors, psychosocial reasons, appearance, etc. McCormack and Fortnum conducted a study on reasons why people fitted with HA do not wear them. The study concluded that the most important issues were about the value of a hearing aid. Often a hearing aid does not provide enough benefit, or wearing a HA is not comfortable [18].

Similar results were also reported by several other studies $[19,20]$. These findings support the hypothesis that put forward inflammation in the middle ear may alter the permeability of round window membrane (RWM); therefore the bacteria and their remnants, for example, endotoxins, may perhaps pass through and adversely affect the inner ear functions, especially the high-frequency region which is anatomically located next to the round window $[21,22]$. 
The RWM is the only soft tissue and very thin structure that separates the inner ear from the middle ear. As a consequence, the assumption is made that inner ear damage happens as the effects of changes in the permeability of the RWM. To apprehend better the pathogenesis of inner ear impairment caused by middle ear inflammation or infection, the RWM structure was best investigated in rat models [23]. Several studies reported inflammatory cell infiltration and penetration of bacteria into the RWM and neighboring scala tympani $[24,25]$.

\section{Conclusions}

The number of patients revealed the presence of SNHL is quite significant. The statistical analysis further highlights the worse impact on $\mathrm{BC}$ thresholds due to the protracted course of the disease, which is inevitably associated with recurrent middle ear infections. The measures for early surgical treatment are recommended to avoid progressive hearing loss in these cases.

\section{Additional Information \\ Disclosures}

Human subjects: Consent was obtained by all participants in this study. Liaquat University of Medical and Health Sciences issued approval LUMHS/REC/-892. Animal subjects: All authors have confirmed that this study did not involve animal subjects or tissue. Conflicts of interest: In compliance with the ICMJE uniform disclosure form, all authors declare the following: Payment/services info: All authors have declared that no financial support was received from any organization for the submitted work. Financial relationships: All authors have declared that they have no financial relationships at present or within the previous three years with any organizations that might have an interest in the submitted work. Other relationships: All authors have declared that there are no other relationships or activities that could appear to have influenced the submitted work.

\section{References}

1. Matsuda Y, Kurita T, Ueda Y, Ito S, Nakashima T: Effect of tympanic membrane perforation on middle-ear sound transmission. J Laryngol Otol Suppl. 2009, 123:81-89. 10.1017/S0022215109005155

2. Wright D, Safranek S: Treatment of otitis media with perforated tympanic membrane . Am Fam Physician. 2009, 79:650-654.

3. Chronic suppurative otitis media (CSOM). (2016). Accessed: March 07, 2020: https://gpnotebook.com/simplepage.cfm?ID=-435814389.

4. Verhoeff M, Van EL, Rovers MM, Sanders EAM, Schilder AGM: Chronic suppurative otitis media: a review . Int J Pediatr Otorhinolaryngol. 2006, 70:1-12. 10.1016/j.ijporl.2005.08.021

5. Chronic suppurative otitis media: clinical features and diagnosis . (2018). Accessed: April 07, 2020: https://www.uptodate.com/contents/chronic-suppurative-otitis-media-csom-clinical-features-anddiagnosis\#H1499469691.

6. Orji FT: A survey of the burden of management of chronic suppurative otitis media in a developing country Ann Med Heal Sci Res. 2013, 3:598-601.

7. Elemraid MA, Brabin BJ, Fraser WD, et al.: Characteristics of hearing impairment in Yemeni children with chronic suppurative otitis media: a case-control study. Int J Pediatr Otorhinolaryngol. 2010, 74:283-286. 10.1016/j.ijporl.2009.12.004

8. Ologe F, Nwawolo C: Prevalence of chronic suppurative otitis media (CSOM) among school children in a rural community in Nigeria. Niger Postgr Med J. 2002, 9:63-66.

9. Ibekwe TS, Nwaorgu OGB: Classification and management challenges of otitis media in a resource-poor country. Niger J Clin Pract. 2011, 14:262-269. 10.4103/1119-3077.86764

10. Adoga A, Nimkur T, Silas O: Chronic suppurative otitis media: socio-economic implications in a tertiary hospital in northern Nigeria. Pan Afr Med J. 2010, 4:3. 10.4314/pamj.v4i1.53613

11. Prakash R, Juyal D, Negi V, Pal S, Adekhandi S, Sharma M, Sharma N: Microbiology of chronic suppurative otitis media in a tertiary care setup of Uttarakhand state, India. N Am J Med Sci. 2013, 5:282-287. 10.4103/1947-2714.110436

12. Papp Z, Rezes S, Jókay I, Sziklai I: Sensorineural hearing loss in chronic otitis media . Otol Neurotol. 2003, 24:141-144. 10.1097/00129492-200303000-00003

13. Ahmed MS, Akhtar S, Ali A, Adeel M, Ahmad AN: Insidious sensorineural hearing loss in chronic suppurative otitis media. Journal of Sheikh Zayed Medical College. 2018, 9:1318-1320.

14. Paparella MM, Morizono T, Le CT, et al.: Sensorineural hearing loss in otitis media . Ann Otol Rhinol Laryngol. 1984, 93:623-629. 10.1177/000348948409300616

15. El-Sayed Y: Bone conduction impairment in uncomplicated chronic suppurative otitis media . Am J Otolaryngol. 1998, 19:149-153. 10.1016/s0196-0709(98)90079-5

16. Yoshida H, Miyamoto I, Takahashi H: Is sensorineural hearing loss with chronic otitis media due to infection or aging in older patients. Auris Nasus Larynx. 2009, 36:269-273. 10.1016/j.anl.2008.07.004

17. Types of hearing loss. (2020). Accessed: April 07, 2020: https://www.healthyhearing.com/help/hearingloss/types.

18. McCormack A, Fortnum H: Why do people fitted with hearing aids not wear them? . Int J Audiol. 2013, 52:360-368. 10.3109/14992027.2013.769066

19. Noordzij JP, Dodson EE, Ruth RA, Arts HA, Lambert PR: Chronic otitis media and sensorineural hearing loss: is there a clinically significant relation. Am J Otol. 1995, 16:420-423.

20. Levine BA, Shelton C, Berliner KI, Sheehy JL: Sensorineural loss in chronic otitis media. Is it clinically significant?. Arch Otolaryngol Head Neck Surg. 1989, 115:814-816. 10.1001/archotol.1989.01860310052021 


\section{Cureus}

21. Amali A, Hosseinzadeh N, Samadi S, Nasiri S, Zebardast J: Sensorineural hearing loss in patients with chronic suppurative otitis media: is there a significant correlation?. Electron Physician. 2017, 9:3823-3827. $10.19082 / 3823$

22. Goycoolea M V, Paparella MM, Juhn SK, Carpenter AM: Oval and round window changes in otitis media. Potential pathways between middle and inner ear. Laryngoscope. 1980, 90:1387-1391.

23. Yoon YJ, Hellstrom S: Ultrastructural characteristics of the round window membrane during pneumococcal otitis media in rat. J Korean Med Sci. 2002, 17:230-235.

24. Jiang S, Seale TW, Gan RZ: Morphological changes in the round window membrane associated with Haemophilus influenzae-induced acute otitis media in the chinchilla. Int J Pediatr Otorhinolaryngol. 2016, 88:74-81. 10.1016/j.ijporl.2016.06.049

25. Schachern P, Tsuprun V, Cureoglu S, Ferrieri P, Briles D, Paparella M, Juhn S: The round window membrane in otitis media: effect of pneumococcal proteins. Arch Otolaryngol Head Neck Surg. 2008, 134:658-662. 10.1001/archotol.134.6.658 